\title{
LA PROTECCIÓN DEL PATRIMONIO PÚBLICO A TRAVÉS DE INSTRUMENTOS ADMINISTRATIVOS
}

\author{
JORGE BERMÚDEZ SOTO*
}

RESUMEN: El patrimonio público consiste en un conjunto de bienes y recursos con que cuenta la Administración del Estado para lograr sus cometidos. Dichos cometidos crecen de manera exponencial en cantidad y complejidad producto de los cambios que experimenta la sociedad. Estos cambios ban incidido en la evolución del Derecho Administrativo, el cual se rige por principios y cuenta con instrumentos y formas de actuación nunca vistos hasta ahora. Tales formas de actuación plantean desafíos para la vigencia del principio de probidad y por ende para la protección del patrimonio público. Por su parte, los fenómenos de corrupción tienen una incidencia directa en la protección del patrimonio público y en la vigencia del principio de probidad. El Derecho Administrativo chileno cuenta con un catálogo de instrumentos destinados a la protección del patrimonio público, los cuales, sin embargo, carecen de un análisis dogmático y de eficiencia que permitan identificar su verdadero potencial.

Palabras Clave: Patrimonio público - Probidad y corrupción Evolución del Derecho Administrativo.

\section{PROTECTION OF PUBLIC HERITAGE THROUGH ADMINISTRATIVE MEANS}

ABSTRACT: The public heritage consists of a set of goods and resources that the State Government has in order to accomplish its duty. Such duties grow in quantity and complexity in an exponential way due to the changes experienced by the society. These changes have influenced the evolution of Administrative Law, which is ruled by principles and counts with means and ways of acting never seen before. Such ways of acting pose challenges to the effectiveness of the probity principle and thus to the protection of public heritage. On the other hand, the corruption phenomena have a direct impact on the protection of public heritage

\footnotetext{
Doctor en Derecho por la Universidad Autónoma de Madrid (España), Profesor de Derecho Administrativo en la P. Universidad Católica de Valparaíso (Chile). Correo electrónico: jorge.bermudez@ucv.cl. El presente artículo corresponde al proyecto FONDECYT $\mathrm{N}^{\circ} 1060816$.

Fecha de recepción: 9 de marzo de 2007.

Fecha de aceptación: 24 de mayo de 2007.
} 
and the effectiveness of the probity principle. The Chilean Administrative Law counts on a catalogue of means intended to the protection of public beritage, which lack, however, of a dogmatic and efficiency analysis that allow to identify its real potential.

KEY WORDS: Public heritage - Probity and corruption - Evolution of Administrative Law.

SuMARIo: 1. Introducción. 2. El nuevo Derecho Administrativo y su incidencia en la protección del patrimonio público. 3. Concepto legal de probidad administrativa y su relación con la protección del patrimonio público. 3.1 Marco legal de la probidad. 3.2 Corrupción. 3.3 Probidad, corrupción y protección del patrimonio público. 4. Instrumentos administrativos que favorecen la protección del patrimonio público. 4.1 Instrumentos preventivos. 4.1.1 Instrumentos directivos. 4.1.2 Instrumentos declarativos. 4.1.3 Instrumentos de garantía. 4.1.4 Instrumentos de procedimentales. 4.2 Instrumentos reactivos. 4.2.1 Instrumentos de acceso a la información. 4.2.2 Instrumentos de inspección y auditoría. 4.2.3 Instrumentos de investigación. 4.2.4 Instrumentos de examen y juzgamiento. 4.2.5 Instrumentos represivos. 5. Observaciones finales. 6. Bibliografía.

\section{INTRODUCCIÓN ${ }^{1}$}

Una pregunta que en el último tiempo ha resurgido con más fuerza es si en Chile han aumentado los fenómenos de corrupción y por ende si producto de ellos se está vulnerando de manera incontrolada el patrimonio público. La denominada agenda de transparencia y probidad impulsada por el actual gobierno parece ser una respuesta positiva a dicha pregunta, y una tácita confirmación de que al menos los instrumentos administrativos para la protección del patrimonio público no han dado el resultado esperado.

En efecto, en el Derecho Administrativo chileno existe un cúmulo de instrumentos administrativos que de forma directa o indirecta tienen como finalidad asegurar la integridad del patrimonio público. Sin embargo, hasta ahora ha existido escaso tratamiento de los mismos, a la luz de la evolución reciente del Derecho Administrativo y, sobre todo, de la consagración formal del principio de probidad administrativa. Ello plantea un escenario de escasa información relativa a los caracteres, clasifica-

Abreviaturas: CPR: Constitución Política de la República; DFL: Decreto con Fuerza de Ley; DL: Decreto Ley; LBGAE': Ley $\mathrm{N}^{\circ} 18.575$ orgánica constitucional sobre bases generales de la Administración del Estado; LBPA: Ley $\mathrm{N}^{\circ}$ 19.880, que establece sobre bases de los procedimientos administrativos que rigen los actos de la Administración del Estado. 
ción y eficacia de los instrumentos que garantizan la protección del patrimonio público en el Derecho Administrativo chileno.

Desde la perspectiva dogmática el problema se plantea aún más complejo, toda vez que ni tan siquiera existe una conceptualización de lo que debe entenderse por patrimonio público. La doctrina más tradicional lo entiende como los recursos y bienes que en el sentido más amplio pertenecen al Estado, independientemente de la forma en que este se organice $^{2}$.

En este trabajo se analizarán en primer término cuáles son los alcances de los cambios que está experimentando el moderno Derecho Administrativo (infra 2), para luego plantear la vinculación que existe entre probidad, corrupción y protección del patrimonio público (infra 3). Más adelante (infra 4) se realizará una categorización y explicación de los diversos instrumentos existentes en el ordenamiento jurídico administrativo chileno destinados a la protección del patrimonio público, para concluir con unas observaciones finales al modo de conclusiones de lo expuesto (infra 5).

\section{El NUEvo Derecho Administrativo y SU inCidenCia EN LA PROTECCIÓN DEL PATRIMONIO PÚBLICO}

El conjunto de tareas que la Administración del Estado hoy día asume, impulsadas por el aumento de las prestaciones que directa o indirectamente debe otorgar para la satisfacción de necesidades públicas, en principio, debería conllevar un aumento en las organizaciones que componen la Administración. Frente a este eventual crecimiento, en la práctica la Administración se ha visto obligada a una diversificación de las fórmulas organizativas en que se estructura la Administración Pública y a un replanteamiento de la forma en que esta gestiona los recursos públicos. Esta situación plantea una multiplicidad de caracteres nuevos para el Derecho Administrativo moderno, los cuales no se encuentran del todo estudiados.

Estos nuevos caracteres de la Administración Pública pueden ser concretizados en los siguientes fenómenos:

- Descentralización funcional: un cúmulo de tareas y cometidos se entregan a Administraciones especializadas, dependientes de la Administración Pública tradicional, aunque separada y autónoma. Si con la descentralización territorial la Administración Pública se

2 Cfr. Silva Cimma, Enrique, Derecho Administrativo Chileno y Comparado. El control público, $4^{a}$ edición, Ed. Jurídica de Chile, 1992, p. 237. 
acerca al lugar en que la toma de decisiones debe llevarse a cabo, con la funcional la Administración adquiere un grado de especialización técnica en aquellos ámbitos en que se asumen nuevas prestaciones. Tal es el caso de la creación de organismos específicos para desarrollar funciones con complejidad técnica (por ejemplo, en materia ambiental, biotecnología, en relación con ciertos grupos como ancianos o indígenas, etc.).

- Fondos: la creación de entidades que tienen como función la administración de patrimonio público con una finalidad determinada. En ocasiones el legislador ha optado por crear fondos que carecen de una estructura orgánica y cuya principal función es administrar recursos públicos con una determinada finalidad. Tal es el caso, por ejemplo, de los fondos creados en la ley general de pesca y acuicultura, en la cual se crean tres fondos diversos, el Fondo de Fomento a la Pesca Artesanal; el Fondo de Investigación Pesquera; y el Fondo de Administración Pesquero. Todos estos fondos tienen en común que carecen de una estructura orgánica, y a lo sumo cuentan con un consejo directivo, que toma la decisión respecto de la inversión de dichos fondos. Sin embargo, toda la administración se lleva a cabo por funcionarios dependientes de la verdadera la Administración Pública, en este caso la Subsecretaría de Pesca. En otros ámbitos la solución ha sido la tradicional. Por ejemplo, en materia de superación de la pobreza, existe el Fondo de Solidaridad e Inversión Social, el cual se crea como un servicio público funcionalmente descentralizado, con personalidad jurídica y patrimonio propio, cuya finalidad es financiar en todo o parte planes, programas, proyectos y actividades especiales de desarrollo social (art. 7 Ley $\mathrm{N}^{\circ} 18.989$, orgánica del FOSIS).

- Huida del Derecho Administrativo: fenómeno que se traduce en la utilización instrumental de las formas organizativas y relacionales privadas que mejor se acomodan a la acción administrativa y a sus finalidades. Así la Administración Pública asume formas de organización del tipo jurídico-privado. La Administración pasa, con toda normalidad, a constituir o a participar en empresas o sociedades regidas por el Derecho privado. La existencia de un Derecho estamental como el administrativo, aplicable a la Administración Pública, no obsta a que esta pueda someter algunas de sus relaciones al Derecho común y, por ende, a la jurisdicción ordinaria. Por ejemplo, la Administración Pública desarrollando actividades comerciales o industriales recurre a formas jurídicas privadas, atendida su mayor eficacia. A ello se suma el fenómeno de la privatización, que no solo supone la venta de empresas públicas o el desprendimiento de funciones tradicionalmente públicas de la Administración, que son asumidas por los particulares, los que las realizan obteniendo un lucro. Se refiere 
también a aquellos casos en que la Administración Pública deja de organizarse bajo la forma de persona jurídica de Derecho Público para, autorizada por la ley, organizarse desde el origen como persona jurídico-privada, por ejemplo como Corporación de Derecho privado, como sociedad anónima, etc.

- Multiplicidad de fuentes: La Administración Pública toma por sí misma gran cantidad de decisiones que antes asumía el Poder Legislativo. Ello exige y supone, para su legitimidad, la incorporación de los ciudadanos interesados, afectados o concernidos por la decisión, en definitiva abrir los procedimientos administrativos a la participación ciudadana ${ }^{3}$. En la práctica este fenómeno se basa en la gran cantidad de remisiones que el legislador hace habitualmente al reglamento. Esta forma de distribución de potestades normativas no se encuentra reconocida expresamente en la Constitución chilena, sin embargo, hoy día es una práctica legislativa común la de reenviar de forma completa la regulación de ámbitos que van mucho más allá del detalle o la particularización de las norma legales. Asimismo, en la aplicación práctica de dichas normas remitidas, sobre todo frente a asuntos técnicos, el reglamento a su vez se remite a resoluciones con carácter normativo, no resolutivo.

- Entrada del principio de cooperación: Consiste en la actuación conjunta de una Administración Pública con los administrados o con otras administraciones públicas, para el logro de un mismo fin, que en general se identificará directa o indirectamente con la satisfacción de necesidades públicas. La idea de la cooperación entre Estado y sociedad domina la discusión científico jurídico-administrativa del Derecho comparado, en especial del alemán ${ }^{4}$. En su trasfondo se encuentra el aumento cuantitativo y cualitativo de las tareas que el Estado asume, la complejidad de las mismas, la disminución de personal y capacidades de la Administración Pública. Todo ello ha llevado a que la idea de la cooperación se transforme en un elemento de conducción política y de desarrollo y ampliación de la actividad estatal, lo que entrega posibilidades de mejorar la situación de déficit de aplicación o eficacia de la normativa. En todas partes, también en Chile, los gobiernos procuran sentarse a la mesa con los actores involucrados en los problemas que se intenta resolver. Los pactos, acuerdos, protocolos, son las diversas manifestaciones en las que se plasma el principio de cooperación. Asimismo, el principio de cooperación encierra tal carga positiva que apenas es posible encon-

Parejo Alfonso, Luciano: Manual de Derecho Administrativo, Vol, I, p. 16, Ed. Ariel Derecho, Barcelona 1996.

4 Para una visión general del tema se puede ver: Peter M. Huber (editor), Das Kooperationsprinzip im Umweltrecht, Ed. Berlin-Spitz, Berlin, 1999. 
trar alguno que se manifieste como detractor u opositor, al menos, a un intento de consenso.

- Actuación informal de la Administración Pública: es aquella forma de actuación de la Administración Pública consistente en: negociaciones, tomas de contacto, presentaciones y acuerdos que se llevan a cabo fuera de un procedimiento administrativo, y que tienen por objeto no ejercer una potestad o ejercerla en una determinada dirección. En realidad la actuación informal es la más común forma de actuación de la Administración, y supone, cuando menos, retraso o suspensión del ejercicio de potestades, toda vez que se trata de que de manera informal la Administración Pública tome contacto con los destinatarios o interesados en sus decisiones o regulaciones, con el objeto de acordar, moderar o dirigir las mismas. La actuación informal requiere de un grado de conocimiento y confianza entre las partes y precisamente estos elementos son los que hacen vulnerable a la Administración frente a las presiones externas.

El esbozo de estos fenómenos que hoy día afectan o caracterizan a la Administración del Estado tienen una incidencia en la protección del patrimonio público. Si la Administración del Estado debe desconcentrarse funcionalmente, atendido el grado de especialidad que la tarea requiere, supondrá que solo algunos podrían, por ejemplo, ser proveedores de esa entidad, limitando la aplicación, por ejemplo, de la licitación pública, como procedimiento administrativo de contratación. Por su parte, la actuación informal de la Administración Pública conlleva un alto grado de eficacia final en la actuación, ya que en muchas ocasiones la resolución o el reglamento han sido previamente acordados con sus destinatarios, pero hace muy vulnerable a la Administración, frente al lobby, y en ocasiones al tráfico de influencias. En el caso de la multiplicidad de fuentes, el fenómeno de la remisión al reglamento provoca como efecto que la discusión de la norma se traslade desde el Congreso Nacional al despacho de una determinada autoridad, con la eventual falta de constancia de la historia de la discusión y aprobación de la norma. Todos estos problemas, como puede apreciarse, pueden llevar a un aumento en la vulnerabilidad del patrimonio público, o una ineficiencia en los instrumentos de protección, tal como se verá más adelante.

\section{CONCEPTO LEGAL DE PROBIDAD ADMINISTRATIVA Y SU RELACIÓN CON LA PROTECCIÓN DEL PATRIMONIO PÚBLICO}

La reforma constitucional de 2005 introdujo un nuevo artículo $8^{\circ}$ a la CPR, el cual en su inciso $1^{\circ}$ dispone que: "El ejercicio de las funciones públicas obliga a sus titulares a dar estricto cumplimiento al principio de pro- 
bidad en todas sus actuaciones" 5 . Se trata de una norma de la más alta jerarquía, incorporada en el capítulo I sobre Bases de la Institucionalidad. En ella se establece como destinatario a toda función pública, con lo que su alcance va más allá de la Administración del Estado. En el ámbito estrictamente administrativo el art. 52 inc. $2^{\circ}$ LBGAE $^{\circ}$ dispone un concepto legal de probidad: "El principio de probidad administrativa consiste en observar una conducta funcionaria intachable y un desempeño honesto $y$ leal de la función o cargo, con preeminencia del interés general sobre el particular".

Esta preeminencia del interés general se encuentra luego desarrollada en el art. 53 LBGAE $^{\circ}$ en cuanto plantea exigencias en los medios con que se realiza la actuación administrativa (medios idóneos de diagnóstico, decisión y control, para concretar una gestión eficiente y eficaz). Y además se expresa o manifiesta en: el recto y correcto ejercicio del poder público; lo razonable e imparcial de las decisiones; la rectitud en la ejecución de las normas, planes, programas y acciones; en la integridad ética y profesional de la administración de los recursos públicos que se gestiona; en la expedición en el cumplimiento de las funciones legales; y en el acceso de los ciudadanos a la información administrativa. Cada una de estas manifestaciones de la preeminencia del interés general se traducen en la aplicación de otros principios e instrumentos administrativos. De dichas manifestaciones se debe destacar la inclusión de la integridad ética y profesional de la administración de los recursos públicos que se gestiona. Ello pone de manifiesto que la vigencia del principio de probidad, en relación con el patrimonio público, se concretiza en la integridad con la que estos deben ser gestionados o administrados. La integridad consistirá en la rectitud, probidad o carácter intachable del administrador. La cual, según el legislador, posee una doble vertiente: ética y profesional. En consecuencia, se vulnera el principio de probidad cuando se afecta al patrimonio público, tanto en cuanto estos se administran con faltas a la ética (por ejemplo, apropiándoselos o malversándolos), pero también cuando el administrador los gestiona de manera diletante, poco capaz o sin dedicación.

La probidad y la preeminencia del interés general plantean el inconveniente en su aplicación, de que se trata de conceptos jurídicos, pero a la vez de carácter ético. En tal sentido, el Derecho Administrativo será un verdadero custodio del comportamiento ético ${ }^{6}$. Si se tratase de conceptos solo jurídicos, estos serían interpretados solo desde la perspectiva

\footnotetext{
5 Cfr. RAJEvic, Enrique, "La inclusión del principio de probidad en la Constitución y la función de control: una necesaria revisión", en Actas de las XXXVI Jornadas de Derecho Público, Facultad de Derecho de la Universidad de Chile, 2006, en prensa.

6 Delpiazzo, Carlos, "Control Social de la Administración y Transparencia", en Ius Publicum, No 11 , año 2003 , p. 49.
} 
legal o técnica, quedando reservado su alcance a los juristas. Al ser también conceptos éticos, su interpretación corresponderá muchas veces a lo que la sociedad en su conjunto estimen como probo o como preeminente para el interés general, alcance que no necesariamente encontrará una manifestación o consecuencia jurídica.

\subsection{Marco legal de la probidad}

El marco legal de la probidad en el Derecho Administrativo chileno puede resumirse en las siguientes disposiciones:

- Ley N ${ }^{\circ} 18575$, Orgánica Constitucional de Bases Generales de la Administración del Estado: Título III de la Probidad Administrativa (Artículos 52 a 68). La cual fue modificada por:

- Ley $\mathrm{N}^{\circ} 19.653$ sobre probidad administrativa.

- Ley $\mathrm{N}^{\circ} 20.000$ nueva ley de drogas.

- Ley $\mathrm{N}^{\circ} 20.088$ declaración jurada patrimonial de bienes (sic).

Complementada a su vez por:

- DS $\mathrm{N}^{\circ}$ 99/00 Reglamento sobre declaración de intereses.

- $\mathrm{DS} \mathrm{N}^{\circ} 45 / 05$ Reglamento sobre declaración patrimonial de bienes.

Asimismo, existen otras normas vigentes en el ordenamiento jurídico chileno con incidencia en la probidad administrativa:

- Convención Interamericana contra la Corrupción.

- DFL N ${ }^{\circ} 29 / 05$ sobre Estatuto Administrativo.

- Ley $\mathrm{N}^{\circ} 19.880$ sobre bases de los procedimientos administrativos.

- Ley $\mathrm{N}^{\circ} 19.886$ sobre contratos administrativos de suministro y prestación de servicios.

- Ley $\mathrm{N}^{\circ} 18.575$ (LBGAE $^{\circ}$ ) normas sobre acceso a la documentación administrativa (arts. 13 y 14).

\subsection{Corrupción}

Se define en términos prácticos como el abuso de un poder que ha sido confiado para obtener un beneficio privado. Desde esta perspectiva corresponde entonces a la antítesis de la vigencia del principio de probidad en cuanto el funcionario ha privilegiado su interés personal por sobre el interés general que le corresponde servir. Sin embargo, la corrupción no necesariamente supone una vulneración a la legalidad formal que se debe respetar en la actuación y ello porque que en virtud del acto de 
corrupción se puede obtener una prestación que puede ser de acuerdo con la legalidad o en contra de ella.

- Prestación Legal: la entrega de un pago, donde el soborno es pagado para recibir un trato preferencial por algo que el sobornado está obligado por la ley a hacer.

- Prestación Ilegal: la facilitación de un pago por un servicio que el sobornado tiene prohibición legal de conceder.

En el primer caso, el acto administrativo que es dictado con ocasión del acto de corrupción no necesariamente se verá afectado directamente por un vicio de nulidad, toda vez que se trata de un acto que en principio igualmente debía expedir la Administración Pública. En cambio en el segundo, el acto administrativo es en sí mismo ilegal, además de la ilegalidad externa proveniente del acto de corrupción.

\subsection{Probidad, corrupción y protección del patrimonio público}

La vigencia del principio de probidad se ve amenazada por los hechos de corrupción, los cuales aparecen presentados por los medios de comunicación como fenómenos de creciente ocurrencia. Evidentemente, si la corrupción trae como consecuencia que la actuación administrativa conlleva un beneficio personal para el administrador, significará que de alguna manera la administración de los recursos públicos no se efectuó con integridad ética ni profesional. En tal sentido la vulneración del patrimonio público se podrá haber producido por:

- Mayor costo: producto del acto de corrupción la Administración Pública incurre en mayores costos al realizar su actuación administrativa o al otorgar una prestación. Ello porque, como resulta evidente, en virtud de un acto de corrupción se adaptan las decisones de la Administración Pública a los fines del propio bienestar sopesando costos y beneficios?

- Pérdida de una ventaja: la Administración Pública deja de aprovechar la ventaja que en un determinado momento se encontraba, por ejemplo un descuento, o un beneficio.

- Infravaloración: la Administración Pública transfiere bienes en un valor que luego se demuestra que había sido tenido a menos, atendido el beneficio que un particular obtuvo, por ejemplo, con su venta posterior a un precio mucho mayor.

Bates, Luis, "Corrupción: concepto y aspectos penales", en Actualidad Jurídica $\mathrm{N}^{\circ} 6$, julio 2002, p. 39. 
- Falta de utilización: la Administración adquiere bienes que luego no son destinados a finalidad alguna o que reciben una aplicación mucho menor a la que hubiere justificado la adquisición.

- Imposibilidad o inutilidad en la aplicación: la Administración encarga la realización de obras o estudios que luego se determinan como inconducentes, mal diseñados o de inútil o imposible aplicación.

En todos estos casos es posible concluir que se ha puesto en riesgo la protección del patrimonio público. Para enfrentar estos fenómenos el Derecho Administrativo ha elaborado un catálogo de instrumentos destinados a contrarrestar los efectos de la falta de vigencia del principio de probidad.

\section{INSTRUMENTOS ADMINISTRATIVOS QUE FAVORECEN LA PROTEC- CIÓN DEL PATRIMONIO PÚBLICO}

En primer término se debe tener en cuenta que por instrumentos administrativos para la protección del patrimonio público debe entenderse el conjunto de normas, procedimientos y acciones concretas que adopta la Administración del Estado para mantener la intangibilidad del patrimonio público. Una clasificación sencilla, pero eficaz, relativa a los instrumentos administrativos existentes para la protección del patrimonio público es aquella que atiende al momento en que operan los instrumentos en relación a la actuación administrativa, esto es, si son anteriores o posteriores a esta. En tal sentido se clasificarán en instrumentos preventivos y reactivos.

\subsection{Instrumentos preventivos}

Dentro de los instrumentos de carácter preventivo se debe distinguir entre los de carácter directivo, declarativo y de garantía.

\subsubsection{Instrumentos directivos}

La vigencia del principio de probidad implica a su vez la observancia de una serie de reglas generales que deben tenerse en cuenta en toda actuación administrativa. Estas reglas son consagradas por el legislador, en ocasiones, como principios o como deberes, todos los cuales tienden a la vigencia del principio de probidad y a la protección del patrimonio público. Entre estos pueden mencionarse:

- Eficacia y eficiencia: los principios de eficacia y eficiencia se encuentran incluidos dentro del listado de principios que deberá observar 
la Administración del Estado en el art. 3 inc. $2^{\circ}$ LBGAE $^{\circ}$. Luego, en el 53 de la misma ley, se menciona como exigencia para la preeminencia del interés general la gestión eficiente y eficaz. En ambos casos las normas citadas discurren sobre una idea de eficacia y eficiencia en la gestión de los asuntos públicos. Esto es, en la obligación de alcanzar un fin y que ello se logre de la manera más económica y proporcionada posible. Por su parte el art. 5 inc. $1^{\circ}$ también de la $\mathrm{LBGAE}^{\circ}$ dispone que las autoridades y funcionarios deberán velar por la eficiente e idónea administración de los medios públicos. En dicha disposición el mandato de eficacia (idónea administración dice la ley) y eficiencia adquiere una connotación mucho más económica, en cuanto se dirige a un aspecto de la gestión económica de los medios públicos. En consecuencia, la protección del patrimonio público se materializa en cumplimiento de los principios de eficacia y eficiencia, en la medida que la gestión del patrimonio público se haga de una manera que no suponga mayores costos a la Administración Pública, y por el contrario, permita alcanzar con la mayor economía de medios la finalidad de la actuación encomendada por el ordenamiento jurídico.

- Imparcialidad: el art. 11 de la LBPA establece el principio de imparcialidad, en los términos siguientes: "La Administración debe actuar con objetividad y respetar el principio de probidad consagrado en la legislación, tanto en la substanciación del procedimiento como en las decisiones que adopte.

Los hechos y fundamentos de derecho deberán siempre expresarse en aquellos actos que afectaren los derechos de los particulares, sea que los limiten, restrinjan, priven de ellos, perturben o amenacen su legítimo ejercicio, así como aquellos que resuelvan recursos administrativos". En estricto rigor en este denominado principio del procedimiento administrativo se establecen dos reglas generales. En primer término se reitera la vigencia del principio de probidad, tanto durante la tramitación del procedimiento administrativo como en la resolución que le pone fin (art. 11 inc. $1^{\circ}$ LBPA). Al mismo tiempo se dispone la obligación de motivar los actos administrativos de contenido negativo o no favorable (que afectaren los derechos de los particulares, sea que los limiten, restrinjan, priven de ellos, perturben o amenacen su legítimo ejercicio) como también los que resuelven los recursos administrativos. Sin embargo, esta disposición es repetitiva, ya que la misma obligación para la Administración se dispone para todo tipo de actuación (favorable o no), ya que el art. 41 inc. $4^{\circ}$ primera frase LBPA dispone que Las resoluciones contendrán la decisión, que será fundada. Más allá de la denominación que se dé a estas reglas generales, lo importante, en atención a la protección del patrimonio público, es la obligación de llevar adelante el procedimiento administrativo y de resolverlo con 
objetividad. En tal sentido, se trata de una obligación que garantiza al menos formalmente que la Administración atenderá solo a los elementos objetivos para su decisión. Asimismo, la obligación de fundamentar la actuación, como también de expresar dichos fundamentos (motivación), constituye una garantía en cuanto deberá exponer ante todos los interesados las razones para una determinada decisión.

- Deber de abstención. El art. 12 LBPA dispone un principio de abstención. "Las autoridades y los funcionarios de la Administración en quienes se den algunas de las circunstancias señaladas a continuación, se abstendrán de intervenir en el procedimiento y lo comunicarán a su superior

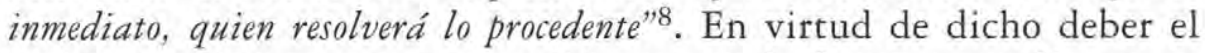
legislador dispone una protección anticipada frente a aquellas autoridades que cuentan con poder de decisión en un procedimiento administrativo y que pueden verse implicadas por los vínculos de parentesco, interés personal en el asunto, amistad o enemistad, vinculación laboral, etc., en el asunto que les corresponde decidir o con las personas que son interesadas en dicha decisión?

\subsubsection{Instrumentos declarativos}

El legislador en la $\mathrm{LBGAE}^{\circ}$ (arts. 57 a 60D) ha dispuesto de tres instrumentos de carácter preventivo declarativo, que tienen por objeto

El inc, $2^{\circ}$ del art, 12 LBPA dispone: "Son motivos de abstención los siguientes:

1. Tener interés personal en el asunto de que se trate a en otro en cuya resolución pudiera influir la de aquel; ser administrador de sociedad o entidad interesada, o tener cuestión litigiosa pendiente con algún interesado.

2. Tener parentesco de consanguinidad dentro del cuarto grado o de afinidad dentro del segundo, con cualquiera de los interesados, con los administradores de entidades o sociedades interesadas y también con los asesores, representantes legales o mandatarios que intervengan en el procedimiento. así como compartir despacho profesional o estar asociado con estos para el asesoramiento, la representación o el mandato.

3. Tener amistad intima o enemistad manifiesta con alguna de las personas mencionadas anteriormente.

4. Haber tenido intervención como perito o como testigo en el procedimiento de que se trate.

5. Tener relación de servicio con persona natural o jurídica interesada directamente en el asunto, o baberle prestado en los dos últimos años servicios profesionales de cualquier tipo y en cualquier circunstancia o lugar.

La actuación de autoridades y los funcionarios de la Administración en los que concurran motivos de abstención no implicará, necesariamente, la invalidez de los actos en que hayan intervenido. La no abstención en los casos en que proceda dará lugar a responsabilidad.

En los casos previstos en los incisos precedentes podrá promoverse inhabilitación por los interesados en cualquier momento de la tramitación del procedimiento.

La inhabilitación se planteará ante la misma autoridad o funcionario afectado, por escrito, en el que se expresará la causa o causas en que se funda". administrativo. 
garantizar la protección del patrimonio público. En primer lugar se deben mencionar dos instrumentos declarativos de carácter directo, tales son la declaración de intereses y la declaración de patrimonio. Si bien es cierto, se trata de instrumentos basados en la propia declaración que hagan los interesados, estos pueden utilizarse como medio de comparación de la envergadura del patrimonio privado al ingresar en la función pública y al término de la misma, o como mecanismo de detección de las posibles incompatibilidades e inhabilidades en la actuación del funcionario. El tercer instrumento de carácter declarativo, ahora de carácter indirecto, es la declaración jurada de no encontrarse en alguna causal de inhabilidad. En este último caso, las inhabilidades mismas son las que protegen el patrimonio público, sin embargo, la forma de hacerla efectiva es también por la vía de la declaración.

- Declaración de intereses: La declaración de intereses deberá comprender las actividades profesionales y económicas en que participe la autoridad o funcionario llamado a efectuarla (art. $58 \mathrm{LBGAE}^{\circ}$ y art. 2 DS N N $^{\circ}$ 99/2000 del Ministerio Secretaría General de la Presidencia). Se trata de una declaración jurada que debe ser actualizada cada cuatro años, o cada vez que exista un hecho relevante que incida en las actividades profesionales y económicas del funcionario. Debe tenerse en cuenta que de acuerdo con lo dispuesto en el art. 87 del Estatuto Administrativo, no es incompatible con la función pública el desempeño de funciones docentes, con un máximo de 12 horas semanales o con el ejercicio de funciones a honorarios desempañadas fuera del horario de trabajo. Sin embargo, el funcionario debe prolongar su jornada de trabajo para compensar las horas de trabajo que utilizó en el desempeño de funciones compatibles (art. 88 Estatuto Administrativo).

- Declaración de patrimonio: consiste en la declaración jurada que algunos funcionarios y autoridades públicas deben practicar (art. 60 $\mathrm{LBGAE}^{\circ}$ ). Esta declaración fue desarrollada a través del DS $\mathrm{N}^{\circ} 45 /$ 05 Reglamento sobre declaración patrimonial de bienes del Ministerio Secretaría General de la Presidencia. Los bienes comprendidos en esta declaración son: "Artículo $6^{\circ}$. La declaración de patrimonio deberá contener una individualización completa de los siguientes bienes del declarante: 1 . Inmuebles de cualquier tipo, que tengan en propiedad, copropiedad, comunidad, propiedad fiduciaria o cualquier otra forma de propiedad; 2. Vehículos motorizados de cualquier tipo, que tengan en propiedad, copropiedad, comunidad u otras formas de propiedad; 3 . Valores a que se refiere el inciso primero del artículo $3^{\circ}$ de la Ley $\mathrm{N}^{\circ} 18.045$ de que el declarante sea titular, esto es, cualesquiera títulos transferibles, sea que se transen en Chile o en el extranjero, tales como acciones, opciones a la com- 
pra y venta de acciones, bonos, debentures, cuotas de fondos mutuos, planes de ahorro, efectos de comercio y, en general, todo título de crédito o inversión. 4. Derechos en comunidades o en sociedades constituidas en Chile o en el extranjero, sea en administración o en capital, que el declarante tenga por sí o a través de sus personas relacionadas. Asimismo, se debe hacer una declaración del pasivo, cuando es superior a 100 unidades tributarias mensuales. La declaración de patrimonio alcanza también a lo bienes del cónyuge, casado bajo el régimen de sociedad conyugal. No obstante, si el cónyuge del declarante fuese mujer, quedarán excluidos de la declaración todos aquellos bienes que esta administre separadamente de conformidad a los artículos 150, 166 y 167 del Código Civil”.

- Declaración jurada de no concurrencia de una inhabilidad: el art. 55 $\mathrm{LBGAE}^{\circ}$ establece como obligación para los postulantes a un cargo de la Administración Pública la declaración jurada que acredite que no se encuentra afecto a alguna causal de inhabilidad prevista en el mismo art. 55. Dichas causales se refieren básicamente a la vinculación contractual con la Administración del Estado o a la vinculación por parentesco o afinidad con otras autoridades o funcionarios. A ella se agrega la inhabilidad que tienen ministros, subsecretarios, jefes de servicio y directivos superiores de la Administración del Estado respecto de la dependencia de sustancias o drogas estupefacientes o sicotrópicas ilegales, a menos que se justifique el consumo por un tratamiento médico (arts. 40 inc. $2^{\circ}$ y 55 bis inc. $2^{\circ}$ LBGAE $^{\circ}$ ).

\subsubsection{Instrumentos de garantía}

Por instrumentos de garantía debe entenderse el conjunto de medidas y reglas adoptadas de forma previa a la entrada en un cargo público que suponga la administración de recursos públicos. El art. 61 letra 1) del Estatuto Administrativo dispone como obligación del funcionario la de rendir fianza cuando en razón de su cargo tenga la administración y custodia de fondos o bienes, de conformidad con la Ley Orgánica Constitucional de la Contraloría General de la República. Por su parte, de acuerdo con lo dispuesto en la Ley Orgánica de la Contraloría General de la República $\mathrm{N}^{\circ} 10.336$, arts. 68 y ss., todo funcionario que tenga a su cargo fondos o bienes fiscales, deberá rendir caución para asegurar el correcto cumplimiento de sus deberes y obligaciones. Esta caución debe efectuarse previamente a la entrada en el cargo o comisión del funcionario. Dicha caución es calificada y aprobada por el Contralor General de la República, y solo podrá consistir en depósitos en dinero en arcas fiscales o en el Banco Central o del Estado a la orden del Contralor General de la República; hipotecas; prendas sobre bonos de la deuda pública; pólizas de seguro o fianzas de responsabilidad personal. El monto de la 
caución se determina por ley o por el Presidente de la República, a propuesta del Contralor General de la República, y en ningún caso puede ser inferior a 2 años de remuneraciones. Por su parte, los Jefes de Servicios deben velar porque este requisito sea cumplido, en caso contrario, serán solidariamente responsables.

\subsubsection{Instrumentos de procedimentales}

Bajo este epígrafe deben entenderse los procedimientos administrativos destinados a la selección de los sujetos privados que contratarán con la Administración del Estado. Se ha definido positivamente a la licitación o propuesta pública como "el procedimiento administrativo de carácter concursal mediante el cual la Administración realiza un llamado público, convocando a los interesados para que, sujetándose a las bases fijadas, formulen propuestas, de entre las cuales seleccionará y aceptará la más conveniente" (art. 7 letra a) Ley 19.886 sobre contratos administrativos de suministro y prestación de servicios $)^{10}$. En virtud de estos procedimientos administrativos se lleva a cabo una asignación de recursos públicos que asegura la igualdad en su distribución, a través de un llamado público y abierto a todos aquellos que tengan interés en participar en la ejecución del contrato administrativo de que se trata, siempre que se cumpla con los requisitos que se señalan $^{11}$. El problema de esta clase de instrumentos procedimentales radica precisamente en las posibilidades que tiene la Administración Pública para exceptuarse a sí misma de su aplicación. Sin embargo, en principio constituyen la mejor vía hasta ahora para asegurar la transparencia y eficacia en la asignación de los recursos públicos contra la prestación consistente en el cumplimiento de una obligación contractual.

\subsection{Instrumentos reactivos}

Por instrumentos reactivos debe entenderse aquel conjunto de medidas administrativas que operaran de forma posterior a la realización de una actuación administrativa que diga relación con la gestión del patrimonio público. Estos instrumentos pueden a su vez estar agrupados según se trate de instrumentos que facilitan la información relativa a una actuación, si la investigan, examinan o juzgan.

10 Por su parte el Reglamento para contratos de obras públicas DS N 75 define licitación como un "Procedimiento mediante el cual se solicitan a proponentes inscritos en el Registro de Contratistas del MOP, o precalificados si es el caso, cotizaciones para la ejecución de una obra pública".

11 Uno de los principales requisitos consiste en estar inscrito en un registro de contratistas. En dichos registros además se lleva una hoja de vida del contratista, respecto de la calificación que se hace de cumplimiento. Otra exigencia previa es la acreditación de la capacidad económica del contratista. 


\subsubsection{Instrumentos de acceso a la información ${ }^{12}$}

EI art. 16 LBPA establece los principios de transparencia y de publicidad. "El procedimiento administrativo se realizará con transparencia, de manera que permita y promueva el conocimiento, contenidos y fundamentos de las decisiones que se adopten en él. En consecuencia, salvo las excepciones establecidas por la ley o el reglamento, son públicos los actos administrativos de los órganos de la Administración del Estado y los documentos que le sirvan de sustento o complemento directo o esencial.

Por su parte, el art. $8^{\circ}$ inc. $2^{\circ}$ CPR dispone que "Son públicos los actos $y$ resoluciones de los órganos del Estado, así como sus fundamentos y los procedimientos que utilicen. Sin embargo, solo una ley de quórum calificado podrá establecer la reserva o secreto de aquellos o de estos, cuando la publicidad afectare el debido cumplimiento de las funciones de dichos órganos, los derechos de las personas, la seguridad de la Nación o el interés nacional".

El principio general de transparencia se expresa en la posibilidad para la generalidad de la comunidad de conocer las actuaciones de la Administración Pública. Se refiere no solo aquellas actuaciones terminales, es decir, el acto administrativo (el que casi siempre posee reglas particulares para darse a conocer), sino de aquellas actuaciones que se producen al interior de cualquier procedimiento administrativo, conduzca o no a la dictación de un acto terminal. Ahora bien, del contraste de ambas disposiciones citadas puede concluirse que hoy día solo en virtud de la ley es posible determinar los casos de reserva o secreto que restringen el acceso a la información administrativa, tanto durante el procedimiento administrativo como en la decisión final, debiendo estimarse que se encuentra derogada la frase del art. 16 LBPA que permite al reglamento establecer excepciones.

El mecanismo previsto para el acceso a dicha información administrativa es el establecido en el art. $13 \mathrm{LBGAE}^{\circ}$. Asimismo, dicho derecho de acceso tiene un amparo judicial en el art. $14 \mathrm{LBGAE}^{\circ}$. Evidentemente, la información por sí sola no garantiza la protección del patrimonio público, sin embargo, solo en base en ella será posible plantear fundadamente una impugnación de una actuación que vulnera el ordenamiento jurídico y, consecuentemente, el patrimonio público. 


\subsubsection{Instrumentos de inspección y auditoría}

El art. 21A. de la Ley $\mathrm{N}^{\circ} 10.33613$ dispone que "La Contraloría General efectuará auditorías con el objeto de velar por el cumplimiento de las normas jurídicas, el resguardo del patrimonio público y la probidad administrativa.

Conforme a lo anterior, a través de estas auditorías la Contraloría General evaluará los sistemas de control interno de los servicios y entidades; fiscalizará la aplicación de las disposiciones relativas a la administración financiera del Estado, particularmente, las que se refieren a la ejecución presupuestaria de los recursos públicos; examinará las operaciones efectuadas y la exactitud de los estados financieros; comprobará la veracidad de la documentación sustentatoria; verificará el cumplimiento de las normas estatutarias aplicables a los funcionarios públicos y formulará las proposiciones que sean adecuadas para subsanar los vacíos que detecte.

El Contralor General establecerá las normas que regularán la forma, el plazo y las modalidades de las auditorías que le corresponda efectuar al organismo fiscalizador.

Sin perjuicio de las atribuciones de la Contraloría General, los servicios públicos sujetos a su fiscalización podrán contratar auditorías de sus estados financieros a empresas particulares externas".

Esta nueva potestad fue establecida expresamente en función de garantizar la protección del patrimonio público, como puede apreciarse en el inciso $1^{\circ}$. Sin embargo, en la propia Ley $\mathrm{N}^{\circ} 10.336$ existía disposiciones que le otorgaban el poder a la Contraloría General para llevar a cabo inspecciones específicas. En efecto, de acuerdo con los arts. 131 y 132 de la Ley $\mathrm{N}^{\circ} 10.336$, el Contralor puede disponer que se constituyan delegados en los Servicios Públicos y en las demás entidades sujetas a su fiscalización para la realización de las inspecciones e investigaciones que estime necesarias. Para dichos efectos el Jefe del Servicio y los funcionarios quedarán bajo la autoridad del delegado para los efectos de proporcionar los datos, informes, documentos y demás antecedentes que el delegado estime necesarios para la investigación.

\subsubsection{Instrumentos de investigación}

Como consecuencia de lo anterior, en la Ley $\mathrm{N}^{\circ} 10.336$ (arts. 131 y ss.) se dispone la posibilidad para el órgano contralor de llevar adelante procedimientos administrativos destinados a determinar la even- 
tual responsabilidad que cabe a los funcionarios en los hechos que se investigan. Evidentemente, se trata de procedimientos administrativos aplicables en general a verificar el cumplimiento de los deberes y obligaciones de los funcionarios públicos, sin embargo, ellos constituyen un instrumento de ejercicio habitual para la protección del patrimonio público.

\subsubsection{Instrumentos de examen y juzgamiento}

La Contraloría General examina las cuentas que deben rendir los funcionarios y personas naturales o jurídicas de derecho privado que manejan bienes o fondos públicos (percepción, recaudación, custodia, administración, pago e inversión de fondos del Fisco). Si a requerimiento de la Contraloría General no se presenta debidamente documentado el estado de la cuenta, el art. 85 inc. $2^{\circ}$ de la Ley $\mathrm{N}^{\circ} 10.336$ dispone que "se presumirá que ha cometido sustracción de dichos valores". Esta cuenta debe ser rendida por meses vencidos (art. 86 Ley $\mathrm{N}^{\circ} 10.336$ ), aunque en determinados casos la Contraloría General podría autorizar un plazo diferente. Esta cuenta debe señalar la forma de inversión de los fondos públicos asignados y se deberá rendir anualmente.

El examen de las cuentas tiene un doble objeto: Fiscalizar la percepción de las rentas e ingresos del Fisco y de las demás entidades y de la inversión de los fondos; comprobar la veracidad y fidelidad de las cuentas, la autenticidad de la documentación y la exactitud de las operaciones aritméticas y de contabilidad. Una vez que se rinde, el Departamento de Contabilidad verifica las eventuales ilegalidades o faltas de la debida cuenta que pueden ocasionar un daño al patrimonio del Fisco. Este es el supuesto a partir del cual se puede iniciar un juicio de cuentas, un reparo fundado en la ilegalidad o falta de la debida cuenta.

La Contraloría General tiene un plazo de un año para realizar el examen de las cuentas, a contar de su recepción. Vencido el plazo, cesa la responsabilidad para el cuentadante, sin perjuicio de la responsabilidad administrativa que afecte a los funcionarios que no realizaron el examen.

Por su parte el Juicio de Cuentas es un procedimiento contencioso administrativo, aunque ambas instancias se llevan a cabo ante un tribunal que podría denominarse como administrativo puro, dado que se realiza ante el subcontralor y en primera instancia y en segunda ante un tribunal colegiado, presidido por el Contralor General. En este caso, el demandado es el funcionario cuentadante y no la Administración, asimismo, no se impugna acto administrativo alguno, sino la veracidad, integridad y complitud de una cuenta. El juicio de cuentas tiene por objeto determinar la responsabilidad civil del funcionario cuentadante y, eventualmente, disponer la aplicación de sanciones. 
A pesar de la importancia que le otorga la Ley $\mathrm{N}^{\circ} 10.336$ al juicio de cuentas, en la práctica se trata de un instrumento administrativo de protección del patrimonio público de poca aplicación ${ }^{14}$.

\subsubsection{Instrumentos represivos}

Los instrumentos represivos con que cuenta la Administración del Estado para asegurar la protección del patrimonio público se encuentran acotados a las posibilidades que tiene la propia Administración de sancionar a sus funcionarios que gestionan recursos públicos. En consecuencia, ellos dicen relación con la posibilidad de imponer sanciones administrativas, las que normalmente en el ámbito funcionarial se denominan medidas disciplinarias. El Estatuto Administrativo dispone de un catálogo de obligaciones (art. 61) y prohibiciones (art. 84) que deben ser observadas por los funcionarios públicos. Algunas de ellas se encuentran directamente relacionadas con el aseguramiento del patrimonio público. Por ejemplo, la obligación de observar estrictamente el principio de probidad (art. 61 letra g); rendir fianza (art. 61 letra 1); o justificarse ante el superior jerárquico de los cargos que se le formulen con publicidad (art. 61 letra m). Por su parte, dentro de las prohibiciones, pueden señalarse como ejemplos las de intervenir en asuntos en que tiene interés (art. 84 letra b); o solicitar hacer prometer o aceptar donativos, ventajas o privilegios (art. 84 letra f); atentar contra los bienes de la institución (art. 84 letra j), etc.

La consecuencia jurídica del incumplimiento de obligaciones y prohibiciones se traducirá en un procedimiento administrativo destinado a determinar la responsabilidad administrativa (investigación sumaria o sumario administrativo) y eventualmente a la aplicación de algunas de las sanciones previstas (censura, multa, suspensión del empleo o destitución).

\section{OBSERVACIONES FINALES}

De lo expuesto en el presente trabajo pueden desprenderse las siguientes observaciones finales:

- El Derecho Administrativo ha sufrido cambios que tienen incidencia en la vigencia del principio de probidad y en la protección del pa-

\footnotetext{
14 Por ejemplo, entre 2001 y 2003 se iniciaron 65 juicios de cuentas. Cfr. BOTTNER, Claudia, "El juicio de cuentas como mecanismo de resguardo al patrimonio público", Memoria de Prueba para optar al grado de Licenciado en Ciencias Jurídicas, PUCV, 2004.
} 
trimonio público. En efecto, si se observa el vertiginoso avance de la sociedad chilena en el mundo globalizado, aparece como una tarea muy difícil para la Administración del Estado la de adecuarse y avanzar a la misma velocidad que aquella. Es por ello que la aparición de nuevas formas de actuación han abierto flancos en que la protección del patrimonio público se pone en riesgo.

- La probidad es fácil de definir; la corrupción solo de describir. La corrupción es la antítesis de la probidad, y a su vez es la enfermedad de debilita la integridad del patrimonio público. Sin embargo, se trata de un fenómeno dinámico, de contornos poco definidos que tan pronto como se define aparece una nueva forma o matiz que vuelve a la carga. Asimismo, en muchas ocasiones la corrupción se acerca mucha a prácticas toleradas, como las del lobby.

- El principio de probidad está presente en toda la legislación administrativa. En consecuencia, la protección del patrimonio público es para el legislador una de las principales preocupaciones a la hora de fijar el ámbito de actuación de las autoridades públicas.

- Los instrumentos administrativos de información y transparencia son eficaces para la protección del patrimonio público. Si bien en este trabajo no se ha efectuado un análisis de eficacia de los instrumentos administrativos, es claro que los instrumentos que favorecen el conocimiento de la actuación administrativa ejercen un efecto preventivo frente a fenómenos de corrupción y afectación al patrimonio público.

- Existe una vinculación directa entre desarrollo y vigencia del principio de probidad. Evidentemente, mientras más intangible sea el patrimonio público, podrán alcanzarse de mejor manera los fines que la Administración del Estado debe lograr por encargo de la sociedad. Un patrimonio público vulnerado o vulnerable genera desconfianza, afecta el tráfico jurídico y en definitiva ralentiza el desarrollo.

\section{BIBLIOGRAFÍA}

- Allesch, Johann y OBANDO, Iván, "Una visión crítica sobre la normativa de acceso a los actos e información administrativa”, en I us et Praxis, año $10 \mathrm{~N}^{\circ} 2,2004$.

- Astorquiza, Gastón, "Legislación, Control y Cultura de Probidad", en Revista de Derecho Público Contemporáneo, octubre-noviembre de 2004.

- BATES, Luis, "Corrupción: concepto y aspectos penales", en Actualidad Jurídica $\mathrm{N}^{\circ}$ 6, julio 2002.

- Delpiazzo, Carlos, "Control Social de la Administración y Transparencia", en Ius Publicum, $\mathrm{N}^{\circ} 11$, año 2003. 
- Huber, Peter M. (editor), "Das Kooperationsprinzip im Umweltrecht", Ed. Berlin-Spitz, Berlin 1999.

- Huidobro, Ramón, "El principio de probidad Administrativa (Notas sobre dictámenes de la Contraloría General de la República)", en Ius Publicum, $\mathrm{N}^{\circ}$ 12, año 2004.

- Parejo, Luciano, Manual de Derecho Administrativo, Vol. I, p. 16, Ed. Ariel Derecho, Barcelona 1996.

- Poblete, Julia, "Publicidad de los actos de la Administración", en Gaceta Jurídica, N $\mathrm{N}^{\circ}$ 300, año 2005.

- Rajevic, Enrique, "La inclusión del principio de probidad en la Constitución y la función de control: una necesaria revisión", en Actas de las XXXVI Jornadas de Derecho Público, Facultad de Derecho de la Universidad de Chile, 2006, en prensa.

- ReYes, Jorge, "Probidad y Corrupción, en Revista de Derecho de la Universidad Austral de Chile, Vol. VI, diciembre de 1995.

- Silva Cimma, Enrique, Derecho Administrativo Chileno y Comparado. El control público, 4a edición, Ed. Jurídica de Chile, 1992. 